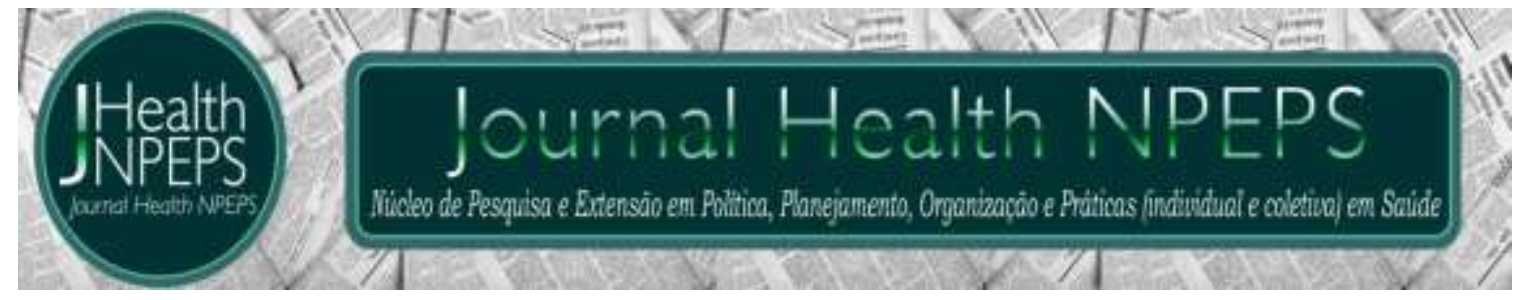

http://dx.doi.org/10.30681/252610104340

RELATO DE EXPERIÊNCIA

\title{
Estratégias de integração com a associação de usuários de um centro de atenção psicossocial
}

\section{Integration strategies with the association of users of a psychosocial care center}

\section{Estrategias de integración con la asociación de usuarios de un centro de atención psicossocial}

\section{Jeferson Rodrigues ${ }^{1}$, Fernando Kimura ${ }^{2}$, Mariana Eleonora Behr Nunes ${ }^{3}$, Patrícia Antônio Fortunato Barreto ${ }^{4}$, Ana Maria Lima da Luz ${ }^{5}$}

\section{RESUMO}

Objetivo: descrever a experiência de integração com associação de usuários de um centro de atenção psicossocial. Método: relato de experiência, construído a partir da realização de uma disciplina de coordenação de grupos e equipes, com membros de uma associação de usuários de um centro de atenção psicossocial do município de Florianópolis, no período de agosto a dezembro de 2019. Resultados: na perspectiva dos estudantes, a integração teoria, prática e ensino-serviço é fundamental para a consolidação do ensino na formação de psicólogo. A elaboração do projeto, a organização, execução e avaliação contribuiu para aprimoramento de competências e habilidades na condução de grupos. Na perspectiva com a associação, verificou-se que é importante fortalecer estratégias para aliar o sentido singular de cada membro ao sentido coletivo dos ideais de uma associação. Conclusão: o

\footnotetext{
${ }^{1}$ Acadêmico do Curso de Graduação em Psicologia da Universidade do Sul de Santa Catarina (UNISUL). Professor Adjunto IV do Departamento de Enfermagem da Universidade Federal de Santa Catarina (UFSC). Florianópolis. Santa Catarina, Brasil. E-mail: jeferson.rodrigues@ufsc.br ORCID ID: http://orcid.org/0000-0002-8612-9088 Autor principal - Endereço para correspondência: Servidão Cristiano Wanderley Faria, no60, apto 703. Trindade. Florianópolis. Santa Catarina, Brasil CEP: 88040405. ${ }^{2}$ Acadêmico do Curso de Graduação em Psicologia da UNISUL. Florianópolis. Santa Catarina, Brasil. Email: fe.kimura@gmail.com ORCID ID: http://orcid.org/0000-0002-3269-3898

${ }^{3}$ Acadêmica do Curso de Graduação em Psicologia da UNISUL. Florianópolis. Santa Catarina, Brasil. Email: marianabehr.psico@gmail.com ORCID ID: http://orcid.org/0000-0003-3270-0696

${ }^{4}$ Acadêmica do Curso de Graduação em Psicologia da UNISUL. Bolsista Pet-Saúde/ Interprofissionalidade. Florianópolis. Santa Catarina, Brasil. E-mail: patriciaffortunato@gmail.com ORCID ID: http://orcid.org/0000-0002-9103-4606

${ }^{5}$ Psicóloga. Mestre em Psicologia. Professora do Curso de Graduação em Psicologia da UNISUL. Florianópolis. Santa Catarina, Brasil. E-mail: ana.Luz@unisul.br ORCID ID: http://orcid.org/0000-0002$\underline{5100-0196}$
}

Este artigo está licenciado sob forma de uma licença Creative Commons Atribuição 4.0 Internacional, que permite uso irrestrito, distribuição e reprodução em qualquer meio, desde que a publicação original seja corretamente citada. 
ensino da psicologia requer contato com a prática, e que o avanço da prática associativa dos usuários requer planejamento estratégico para promover a identidade e sentido de grupo e lugar de pertença na associação.

Descritores: Psicologia; Associação; Serviços de Saúde Mental.

\section{ABSTRACT}

Objective: to describe the experience of integration with the association of users of a psychosocial care center. Method: experience report, built from a group and team coordination discipline, with members of a user association of a psychosocial care center in the city of Florianópolis, from August to December 2019. Results: from the students' perspective, the integration of theory, practice and teaching-service is fundamental for the consolidation of teaching in the training of psychologists. The elaboration of the project, the organization, execution and evaluation contributed to the improvement of competences and skills in the conduct of groups. From the perspective of the association, it was found that it is important to strengthen strategies to combine the unique meaning of each member with the collective sense of the ideals of an association. Conclusion: teaching psychology requires contact with practice and that the advancement of users' associative practice requires strategic planning to promote the identity and sense of group and place of belonging in the association.

Descriptors: Psychology; Association; Mental Health Services.

\section{RESUMEN}

Objetivo: describir la experiencia de integración con la asociación de usuarios de un centro de atención psicosocial. Método: reporte de caso, construido a partir de una disciplina de coordinación grupal y de equipo, con miembros de una asociación de usuarios de un centro de atención psicosocial en la ciudad de Florianópolis, de agosto a diciembre de 2019. Resultados: desde la perspectiva de los estudiantes, la integración de la teoría, la práctica y el servicio de enseñanza es fundamental para la consolidación de la enseñanza en la formación de psicólogos. La elaboración del proyecto, la organización, la ejecución y la evaluación contribuyeron a la mejora de las competencias y habilidades en la conducción de grupos. Desde la perspectiva de la asociación, se descubrió que es importante fortalecer las estrategias para combinar el significado singular de cada miembro con el sentido colectivo de los ideales de una asociación. Conclusión: la enseñanza de psicología requiere contacto con la práctica y que el avance de la práctica asociativa de los usuarios requiere una planificación estratégica para promover la identidad y el sentido de grupo y lugar de pertenencia en la asociación.

Descriptores: Psicología; Asociación; Servicios de Salud Mental.

INTRODUÇÃO

A formação do psicólogo é constituída pela articulação de conhecimento, competência e habilidades em diferentes contextos e áreas de atuação. A realização de grupos faz parte dos 
recursos que o psicólogo lança mão de sua vida profissional. A fim de desenvolver esta habilidade, a Unidade de Aprendizagem Coordenação de Grupos e Equipes da Universidade do Sul de Santa Catarina propõem aos estudantes realizarem um projeto de intervenção como estratégia de desempenharem recursos iniciais para lidar com grupos. 0 grupo escolhido para a intervenção foi a associação dos usuários de um Centro de Atenção Psicossocial por entender que as especificidades deste grupo correspondiam as necessidades acadêmicas e vice e versa.

As associações de usuários de serviços de saúde mental no Brasil se constituem como ações coletivas que buscam tornar 0 sistema de saúde mental de qualidade para o cuidado. Essas associações são constituídas conforme cada realidade local, com usuários, familiares, profissionais, amigos e estudantes ${ }^{1}$.

Conforme Vasconcelos ${ }^{2}$, o perfil das associações de usuários no campo da saúde mental no Brasil é de associação mista, formada por usuários, familiares e profissionais, ocorrendo a partir da década de 1990 e vinculada a um CAPS. 0 funcionamento das associações se dá com reuniões quinzenais ou mensais e contribuição financeira. As associações seguem os princípios da reforma psiquiátrica, possuem bandeiras da defesa dos direitos do usuário e familiar, e realizam projetos de geração de renda.

Este perfil indica o desafio de consolidar uma base econômica, política e organizacional, que garanta um engajamento cidadão de usuários e familiares vinculados a associação no campo da saúde mental. Entretanto, anterior a esta consolidação, é importante que o lugar e a função de cada pessoa na associação esteja confirmada e esclarecida, para que todos saibam se posicionar em relação às demandas.

Um dos únicos dados estatísticos relativo ao número de associação de usuários no Brasil é do ano de 2010, quando o Ministério da Saúde, por intermédio da Coordenação Nacional de Saúde Mental lançou um cadastro nacional para as associações postarem seus dados. Na época havia cerca de 120 associações de usuários e familiares 
vinculados à saúde mental ${ }^{3}$. Em Santa Catarina, ainda não há registros sobre a presença dessas associações.

As ações das associações requerem sintonia entre os pares, de modo que o trabalho em grupo, tenha objetivos em comuns para serem alcançados. Uma das contribuições da formação de psicólogo com o campo da saúde mental é a colaboração, no momento da formação, com a aplicação de técnica de grupos. A intervenção em grupo a partir da realidade da associação pode possibilitar um planejamento que direcione uma correspondência entre aquilo que se espera e o que se propõem.

A partir da observação participante realizada no dia 06 de setembro de 2019, em uma das reuniões semanais da associação, recebeu-se como demanda explícita a realização de algumas técnicas grupais que contemplassem questões como integração e identidade de grupo, a fim de suprir algumas lacunas existentes na representação política da associação. Sendo necessário, para isso, um movimento de fortalecimento dos membros do grupo, a fim de estimular novas lideranças e desenvolver o sentimento de pertença. Destarte, com a intervenção dos estudantes esperava-se, como resultado, maior envolvimento e responsabilidade de cada membro em relação às atividades do grupo.

Intervenções de grupo baseados no desenvolvimento interpessoal possibilita esta interlocução entre o indivíduo, os membros e em grupo. Parte-se do pressuposto que para as finalidades da associação serem executadas as relações em grupo necessitam de envolvimento, comunicação, sentimento de pertença e cooperação. Segundo Zimerman ${ }^{4}$, o que constitui um grupo como tal é a presença de regras e mecanismos próprios, que representem as especificidades de cada grupo e que haja uma convergência de interesses.

Importa dizer que a integração e uma relação saudável entre o grupo é uma premissa para o fortalecimento dos vínculos e um trabalho articulado e em equipe Um grupo de Desenvolvimento Interpessoal (DI), como apontado 
por Castilho ${ }^{5}$, tem como principal objetivo atingir a sinergia de um grupo a partir do desenvolvimento de habilidades sociais, entre elas: comunicação, respeito às diferenças individuais e "capacidade de dar e receber feedback". Isso acontece a partir de um movimento autônomo no qual o grupo recorre a um líder espontâneo de forma emergencial.

$$
\mathrm{O} \text { enfoque do grupo de DI }
$$
se detém no que Castilho $^{5}$ denomina "aqui-e-agora”, isto é, o momento atual do grupo e seus significados para cada membro, o que contribui para refletir a posição associativa de cada participante. Sobre a importância do aprimoramento na relação interpessoal, Moscovici ${ }^{6}$ contribui com a visão de que o desenvolvimento das habilidades sociais configura as relações interpessoais, que por sua vez é diretamente proporcional à entropia do grupo. O que faz laço entre os participantes para que os vínculos se mantenham forte é algo que 0 grupo interpessoal pode contribuir.

uma convergência entre o modo como

cada associado representa a associação, o sentido que cada membro confere a associação e como entender o lugar que cada um coloca a associação em si para refletir o que mobiliza, qual sua função e como atua nesta Isto porque deve-se convergir 0 interesse pessoal com o interesse institucional. Para Offe ${ }^{7}$ são três interesses que contribuem para as pessoas se organizarem em ações associativas: a) o desejo, a vontade, a identidade com os valores dos membros do grupo; b) o fator econômico e social de onde faz surgir o grupo; c) formas e práticas institucionais que a associação tem como finalidades.

$$
\text { Assim, tem-se como }
$$
questão norteadora: como realizar uma intervenção de integração de grupo com a associação dos usuários do centro de atenção psicossocial? A partir disso, o objetivo do estudo foi descrever a experiência de integração com a associação de usuários de um centro de atenção psicossocial.

\section{MÉTODO}


Trata-se de um relato de experiência. A associação que acolheu a realização da intervenção em grupos por estudantes de psicologia foi criada no ano de 2013 e teve, até o momento atual, fevereiro de 2020, cinco gestões. Em seu estatuto social, as finalidades desta entidade são: a) trabalhar em prol dos usuários do centro de atenção psicossocial, em defesa de políticas públicas de interesse comunitário, com a participação dos moradores, usuários e colaboradores. b) promover atividades sociais, educacionais, culturais e desportivas. c) celebrar convênios e parcerias com associações congêneres, entidades religiosas, civis autarquias, empresas públicas/privadas e órgãos públicos nas três esferas de governo ${ }^{8}$. De certa forma, entende-se que para os membros do grupo se reunirem, mobilizarem e se organizarem para executar as finalidades da associação, necessita-se de recursos que possibilite refletir a convivência, a relação, os valores, os lugares que cada um e cada uma ocupa nessa entidade, para que a unidade possa ser representada na prática.

Para alcançar os objetivos da intervenção em grupo na associação dos usuários foi escolhida a metodologia de desenvolvimento interpessoal proposta por Moscovici ${ }^{9}$. Segundo a autora, quando o grupo aprende sobre o próprio grupo, suas características de constituição e funcionamento, o indivíduo também é obrigado a estudar o seu próprio papel, sua atuação e seu significado para os demais membros e também do grupo como um todo. Quando se promove uma intervenção em caráter experimental, os participantes são encorajados a vivenciar comportamentos diferentes do seu padrão na interação com outros membros do grupo, sem as devidas consequências de uma experiência real.

0 enfoque aqui-e-agora permite que a experiência presente seja o ponto de partida para a aprendizagem, uma vez que ela é comum a todos os membros do grupo. Por ser direta, pessoal, imediata e compartilhada com todos os membros do grupo, a 
experiência poderá ser comparada, apreciada e validada com base em conceitos e

conclusões pessoais/grupais a serem elaborados.

Essa aprendizagem vivencial compreende um ciclo de quatro etapas sequenciais $e$ interdependentes: a) Atividade; b) Análise; c) Conceituação; d) Conexão.

A primeira etapa, consiste na vivência de atividades em que o participante se empenha para uma solução de problema, uma simulação comportamental, dramatização, jogos e outros exercícios. A etapa que segue a vivência é a análise, a qual consiste no exame e discussão ampla das atividades realizadas, na análise crítica dos resultados e do processo para alcançá-los. Para que possa aprender com a experiência é necessário buscar o seu significado através de conceitos esclarecedores. A conceituação é um trabalho realizado em conjunto do coordenador e participantes que permite a conscientização de aspectos pessoais, interpessoais $\mathrm{e}$ grupais, levando a aprendizagens significativas baseadas na vivência de cada um.

Após a conceituação, inicia a etapa de conexão, onde os participantes fazem a correlação com o real comparando aspectos teóricos com situações práticas da vida real. Cada participante elabora suas conclusões para uso futuro, analisa suas perspectivas pessoais e calcula os riscos de aplicação das novas aprendizagens. Ao final, exercita a sua criatividade para planejar táticas de inovação dos procedimentos. Nesta etapa, o participante busca a mudança, experimentando outras formas de conduta que o conduz novamente à primeira etapa de atividade/vivência.

O projeto intervencional foi planejado para cinco encontros, sendo que o primeiro para observar a realidade dos usuários da associação e os demais encontros para a execução das técnicas grupais. Cada encontro foi planejado, por diversos tipos de técnicas grupais ${ }^{10,11}$. Além disso, a prática foi subsidiada pela supervisão do professor responsável e monitores da disciplina.

A prática interventiva foi 
realizada em quatro encontros com duração média de 60 minutos, com um grupo de aproximadamente 15 associados da associação dos usuários do centro de atenção psicossocial. Os encontros aconteceram semanalmente, às sextas-feiras, nas datas 04, 11, 18 e 25 de outubro de 2019, com o horário agendado das 11:00 às 12:00 horas. Cada encontro foi pautado no desenvolvimento grupal (atividade, análise, conceituação e conexão). Através dessa estrutura de fases foi possível estabelecer metas, objetivos e prazo para início e final das intervenções. Para a realização das técnicas foram utilizados instrumentos como: estojo com canetas e lápis de cor, rolo de barbante, revista, jornais, cartolina, computador e caixa de som.

\section{Descrição da experiência}

A experiência dos estudantes será descrita por encontros para seguir o passo a passo do realizado, para que esta experiência possa ser inspiradora para novas intervenções e que a descrição contribua com o processo ensino-aprendizagem

do

profissional psicólogo.

Objetivo do encontro 1: conhecer o grupo, aplicar técnicas que auxiliasse compreender o grupo e como era composto.

Descrição do Encontro: 0 encontro começou com alguns minutos de atraso devido a acontecimentos internos. Havia um grupo de 15 pessoas e atividade se deu no mesmo local onde são realizadas as reuniões semanais da associação. A princípio, cada um dos estudantes se apresentou brevemente e foi explicado para o grupo qual era o propósito dos encontros. Tentou-se escolher pontualmente palavras que pudessem abranger tudo, de forma mais clara e precisa, estando disponível para acolhê-los no que fosse necessário. Nesse momento, percebeu-se o grupo ainda tímido e, talvez, com expectativa sobre o que sucederia.

Foi esclarecido, em seguida, a importância do contrato para um bom funcionamento no grupo, e questionados sobre o que seria necessário para que os encontros acontecessem de maneira agradável e harmoniosa. 
Como parte do aquecimento inespecífico, um aluno coordenou a técnica do Jogo do Andar ${ }^{10}$. A técnica consiste em pedir que as pessoas andem pela sala ouvindo atentamente e seguindo as consignas dadas pelo coordenador. Assim, pediu-se que os membros andassem "imprimindo seu ritmo diário" e que observasse as características de cada passo. Em seguida, trocou-se o ritmo de acordo com as consignas e foi pedido para que observassem os aspectos de cada forma de andar (com as pontas dos dedos, calcanhares, entre outros), intercaladas com o andar normal. Cada membro se manteve atento e seguiu as orientações de maneira precisa, mostrando estarem inteiramente envolvidos naquele momento de introspecção. Após o jogo, todos retornaram aos seus lugares e outro aluno assumiu o papel de coordenação da técnica específica com o Jogo do Novelo ${ }^{10}$.

O Jogo do Novelo iniciou com o coordenador amarrando uma ponta do novelo no dedo e dizendo nome e o que mais gosta de fazer. Ato contínuo, o novelo foi jogado para outra pessoa da roda que repetia o ato e assim por diante. Foi possível perceber que, de certo modo, as consignas dadas pelo coordenador não se fizeram entender e, por um momento, todo o movimento do grupo se deu de maneira difusa como, por exemplo, passando o novelo de lã por debaixo das linhas já esticadas ou esquecendo de amarrar o novelo na ponta do dedo. Novamente, as consignas foram repassadas e os membros do grupo puderam chegar ao final da dinâmica. Com todas as linhas já esticadas, propagou-se um momento de reflexão induzido pelo coordenador, com diferentes questões disparadoras, tais como: "o que acontece com o emaranhado se cada um do grupo puxar bem forte?" e “se experimentássemos largar os fios por um momento? o que aconteceria?". Nesse momento de reflexão, alguns integrantes do grupo utilizaram o novelo como metáfora para designar diversos processos que acontecem no cotidiano da associação, sendo um momento rico para explorar a importância da coesão e da representação de cada integrante. Percebeu-se que não houve participação integral dos membros 
do grupo, talvez por se tratar ainda de um primeiro contato ou, até mesmo, pelo fato de que as atividades não terem mobilizado os membros. No entanto, todos se mantiveram atentos durante 0 momento de reflexão.

Posteriormente, foi solicitado que cada participante retornasse ao seu lugar para darmos início à terceira e última técnica do dia: a técnica das qualidades e manias ${ }^{10}$ conduzida por outra aluna. Foram distribuídos papéis nos quais cada pessoa teve de escrever duas qualidades pessoais, um sonho, uma esperança, um hobby/lazer e o que gosta dentro da associação. Cada um dos estudantes se distribuiu pelo grupo a fim de auxiliar aqueles que porventura tivessem alguma dificuldade para ler ou escrever. No geral, foi possível perceber que a questão "o que gosta dentro da associação?” levantou maior dúvida entre os membros, não havendo respostas aprofundadas sobre 0 assunto.

No final do encontro, outro aluno conduziu o momento de compartilhamento das percepções do grupo acerca de cada atividade.
Um dos relatos mais marcantes foi de um dos membros que, ao falar sobre a técnica de aquecimento (das “pisadas”), conectou ao fato de prestar atenção aos próprios passos e perceber suas particularidades, em diversos momentos teve que prestar atenção aos seus próprios limites fazendo comparação a internação psiquiátrica e o cotidiano no Centro de Atenção Psicossocal e associação.

Quando todos haviam compartilhado, os estudantes entregaram a associação uma caixa com docinhos, como havia acordado no encontro anterior. Um dos doces que mais chamou a atenção foi o "bicho-de-pé" (doce feito com morango e coberto com granulado rosa), cujo nome curioso arrancou risadas do grupo.

Objetivo do encontro 2: conhecer o lugar e função que cada participante ocupa no grupo.

Descrição do encontro: os trabalhos foram iniciados por um aluno que deu boas vindas a todos os presentes e foram feitas as apresentações dos coordenadores. Após, cada participante se apresentou e seguiram-se as 
atividades. A princípio, foi realizado um aquecimento inespecífico no qual sugeriu-se que fosse realizado um caminhar pela sala, respirando, prestando atenção no corpo, soltando ombros e tentando relaxar as partes que estavam tensas.

Como aquecimento específico foi utilizada uma técnica adaptada do caracol que foi conduzida por um aluno. Foi solicitado ao grupo que ficasse em pé, formasse um círculo e que dessem as mãos. A coordenadora entrou na roda segurando a mão de um participante, solicitou que este a acompanhasse para a formação de um grande caracol. Todos os outros deveriam seguir 0 participante a sua frente quando se sentissem puxados. 0 caracol foi se formando lentamente. Ao término da formação, solicitou-se aos participantes sugestões para que o grupo conseguisse retornar a forma inicial, ou seja, um círculo. Uma solução proposta na técnica é que se "abra" um túnel, passando por baixo das mãos entrelaçadas, sendo que OS participantes acompanhassem o coordenador até a forma inicial. Como o caracol foi fechado, um participante apresentou uma ideia diferente do proposto original da técnica. Ele sugeriu inverter o caracol, ou seja, o último participante se tornou 0 líder que conduziu o grupo, desenrolando o caracol para se retornar à posição inicial.

Após o aquecimento, iniciou-se a atividade do quebracabeça conduzida por um aluno. Pediu-se aos participantes que se dividissem em grupos. Foram distribuídos quebra-cabeças e solicitou-se que cada grupo montasse o seu quebra-cabeça e, assim, foi dado um aviso importante: todos os quebracabeças possuíam solução e a resolução deles se encontrava naquele espaço. No entanto, as peças dos quebra-cabeças foram misturadas. Assim, para que um grupo terminasse sua tarefa seria necessário que trocasse informações e peças com os demais grupos. Os participantes foram divididos em três grupos (A, B e C) e as peças de dois quebra-cabeças foram misturadas e distribuídas aleatoriamente entre os grupos.

0 grupo A percebeu rapidamente que a maioria das 
peças não se encaixavam e que faltava peças para resolver 0 problema. Pediram para se juntar ao grupo B para tentarem achar uma solução. Nesse ínterim, o grupo C se fechou entre seus membros e tentavam encontrar uma solução com as peças que dispunham. Os grupos A e B juntaram suas peças e verificaram que havia dois quebra-cabeças a serem montados e perceberam que faltavam peças para a solução do problema e que elas só poderiam estar com o grupo C. Juntaram-se os três grupos e solucionaram o problema.

Pediu-se que eles compartilhassem 0 que experienciaram na técnica. Após os relatos, o que se observou foi que maioria reconheceu o sentido de grupo, pois vários participantes relataram que existem problemas e que a solução está em se comunicar e fazer trocas com os outros e que, às vezes, com os recursos que se dispõe, é inviável chegar à solução de um problema sozinho.

Logo após, foi realizada a técnica da mandala. Essa técnica foi coordenada por outro aluno. Foi distribuído tiras de papéis e canetas aos participantes. 0 coordenador solicitou que cada membro do grupo pensasse em uma palavra que representasse a associação, as relações dentro da associação ou ainda, o que era necessário para 0 bom funcionamento da associação. Pediu que os participantes escrevessem a palavra pensada em uma tira de papel. Caso tivessem mais de uma palavra, que essa foi também escrita em outra tira.

Após cada membro escrever sua(s) palavra(s), as tiras foram lidas, contadas e as palavras repetidas foram agrupadas. Ao final, perguntou-se ao grupo por ordem de quantidade de vezes que a palavra apareceu se ela representava o grupo. Caso a resposta fosse afirmativa, a tira com a palavra era colada em um cartaz. As palavras que mais apareceram foram: organização, união, planejamento, loucura/paixão, respeito, seriedade, atividades, direitos, comida e força.

Com estas palavras e outras que apareceram em menor número foram feitos dois cartazes. Ao final, foi pedido que cada participante 
olhasse para o cartaz e visualizasse as palavras que representavam a associação e que aquele trabalho deveria ser colado em um lugar visível para servir de orientação nas decisões da associação. Foi refletido sobre como colocar em atitude, em ato no cotidiano da associação aquelas palavrasvalores. Foi distribuído sorvete conforme combinado no encontro anterior.

Objetivo do encontro 3: identificar os objetivos comuns e incomuns dos participantes e que refletissem nas características da associação.

Descrição do encontro: 0 encontro teve início com boas vindas por um aluno, que saudou e desejou que a manhã fosse divertida e de aprendizagens. Explicou que tratava de uma atividade de grupo e de continuidade e que nesse dia seria o terceiro encontro. Foi realizado a apresentação dos alunos e em seguida os participantes falaram seus nomes. Ato contínuo foi realizado o aquecimento conduzido por outro aluno.

0 aquecimento realizado foi escolhido a partir da supervisão com o professor e monitores, baseado na literatura de Yozo ${ }^{10}$. Foi aplicado o aquecimento “dança das dobradiças", cujo material era música e a instrução era o grupo ficar em pé e em círculo para que pudessem dançar com o corpo todo e alternarem com as consignas do coordenador. As consignas eram dançar somente com os pés e tornozelos; somente com as pernas; somente com os quadris; somente com o tórax; somente com 0 pescoço e cabeça; somente com olhos e boca. No final, todos caminhavam pela sala e retornavam ao lugar de origem ${ }^{10}$. Destarte, a música foi tocada Pharrell Williams - Happy e todos começaram a dançar. Um aluno dava as consignas e os movimentos eram alterados. Observou-se que todos participaram, dançaram e houve descontração entre os membros.

A segunda técnica utilizada foi uma adaptação do papel - um objeto intermediário. Esta foi escolhida através de supervisão com o docente e monitores. 0 material foi papel A4 com questões impressas. As instruções constavam que cada pessoa recebesse uma folha de papel com questões e o 
coordenador explicasse 0 que deveria ser escrito. Depois cada um falou das respostas ${ }^{10}$.

Os participantes sentaram nas cadeiras em círculo e um aluno situou a técnica, o objetivo e a combinação de que qualquer ocorrência os alunos coordenadores acompanhariam, a exemplo, se alguém tivesse problema para ler e escrever. Todos os participantes aderiram a técnica. Os quatro alunos coordenadores auxiliaram alguns participantes e, após estes terem respondido as questões norteadoras, foi realizado uma roda de conversa para quem quisesse compartilhar, tendo como ordenamento uma rodada de fala a partir da primeira questão, finalizava, e sucedia a próxima.

A primeira questão versava sobre "qual lugar a pessoa ocupa na associação", ao passo que alguns responderam que não sabiam, alguns que eram usuários do CAPS, outros eram participantes e membros da gestão. Foi ausente a indicação de sócio e associado. $\mathrm{Na}$ segunda questão "o que faço na associação" houve trabalhar no brechó, participar da associação, lutar pelos direitos, participar de passeio, associação como espaço terapêutico. Na terceira questão "o que posso dar para a associação" foi comentado que se daria 0 tempo, a presença e a participação. Na quarta questão “o que a associação pode dar para mim" obteve-se espaço de luta, espaço de organização, espaço para vender objeto no brechó, fazer passeio.

No compartilhamento, o aluno que conduziu a técnica refletiu que 0 que traz os participantes ali é a história de cada um e perguntou qual era a história deles com a associação e qual a história da associação. Que era importante terem curiosidade, interrogações sobre a associação, o lugar de cada um nela, qual a função que cada um tem na associação e qual a função que a associação tem na vida de cada um. Quais caminhos poderiam buscar coletivamente para encontrarem respostas, quais documentos indicam respostas. Os coordenadores agradeceram e foi ofertado frutas aos participantes conforme combinado em encontro anterior. 
Objetivo do encontro 4: identificar a contribuição de cada participante no grupo e a representação desta para si e para o grupo.

Descrição do encontro: o encontro do grupo teve início com uma breve apresentação dos coordenadores e dos objetivos do grupo por um aluno, o mesmo explicou que tratava da continuidade de outros três encontros e que nesse dia seria o quarto e último encontro. Como aquecimento, um aluno aplicou a técnica "Balão dos Sonhos", para tal foram utilizados os materiais: balões e palitos de dentes ${ }^{10}$. No início da técnica o coordenador convidou o grupo a formar um círculo em que todos estivessem em pé, entregando um balão para cada participante e solicitando que cada um pensasse em um sonho e enchesse 0 balão que tinha em mãos. Alguns associados apresentaram dificuldades em encher e/ou amarrar o balão e receberam ajuda dos coordenadores. Com todos os balões cheios, cada participante ganhou um palito de dente, todos receberam a consigna de caminharem aleatoriamente pela sala e protegerem seus balões e seus sonhos. Com o início da caminhada, os participantes reagiram à atividade estourando os balões uns dos outros. Depois que todos os balões foram estourados, 0 coordenador questionou "qual o objetivo da atividade? A ordem era de estourar os balões?". Os associados demonstraram um pequeno desconforto e resistência frente ao questionamento.

Em um segundo momento, outro aluno propôs a técnica de ilha do tesouro ${ }^{10}$. Foram dispostos jornais de um lado da sala e na outra extremidade uma caixa de bombons sobre um jornal que seria a "ilha do tesouro". Os associados foram convidados a se posicionarem em cima dos jornais, nesse momento uma parte do grupo ficou nos jornais e outra parte ficou de fora para ajudá-los a resolver o desafio. Quando todos estavam prontos, foi dada a explicação de que cada um deveria permanecer em pé, em cima da folha de jornal, sem sair da área do jornal, sem pisar no chão, e deveria tentar chegar até a ilha, e que o jornal deveria ser movido, mas não 
rasgado. Iniciada a técnica, os associados focaram em chegar à ilha individualmente, com isso dois jornais acabaram sendo rasgados e estes participantes saíram da atividade. Passaram alguns minutos e nenhum associado encontrou uma solução coletiva para chegar e alcançar seu objetivo. Dois participantes foram arrastando devagar seus jornais e chegaram ao tesouro, os demais se moveram alguns centímetros tentando replicar a mesma estratégia observada.

Com isso, o coordenador pediu uma pausa na técnica $\mathrm{e}$ perguntou como eles poderiam chegar ao tesouro para além da forma conseguida pelos dois participantes. Nesse momento, não houve uma elaboração de possíveis estratégias coletivas e 0 coordenador começou a dar pistas para que o grupo chegasse à uma solução. Como o grupo estava com dificuldade, foi mostrada uma alternativa de solução e com isso o grupo conseguiu alcançar à "ilha". A caixa de bombons foi dividida com todos os membros do grupo, como recompensa pela participação e como mérito por terem alcançado o objetivo.

Durante a realização da atividade, observou-se que os participantes que estavam de fora do jornal para ajudar os que precisavam alcançar a ilha, mantiveram-se em silêncio e não trouxeram soluções. Um aluno fez uma reflexão do porquê quando é solicitado algo já saem fazendo sem ter um planejamento, sem consultar o que as pessoas pensam. Alguns comentaram que isso é algo que precisa ser revisto, que em se tratando de uma associação as ações devem ser coletivas e comentaram que os valores de solidariedade e união estavam presentes. 0 coordenador pediu que eles mostrassem através de gesto (retomou-se a cena) onde que a união e a solidariedade estavam presentes na cena. Comentaram que estavam presentes na formação da dupla, no respeito que tiveram pelo contexto e ficou a reflexão de como colocar a união na prática.

Em terceiro momento, o grupo foi convidado a se sentar em roda pelos coordenadores. Nesse momento, fez-se uma retrospectiva 
do último encontro e dos encontros anteriores, conversando sobre a atuação do grupo frente ao objetivo de integração, identidade e trabalho em grupo. Abordou-se o fato do grupo estar com dificuldade para realizar a técnica anterior $\mathrm{e}$ como isso refletia no cotidiano deles. Um aluno fez um questionamento do porquê o grupo não ter se comunicado entre si quando recebeu a consigna de alcançar 0 tesouro. Houve comentários por parte de alguns que este era um ponto que precisava ser revisto, já que em encontros anteriores houve 0 reforço de que um dos valores do grupo era a união, inclusive de que por se tratar de uma associação as ações precisam ser coletivas. Ficou a reflexão de como colocar a união na prática. Teve um membro que justificou a dificuldade de cumprimento das técnicas, pois as consignas não estavam claras para ele ou subentendidas como no caso dos balões. Houve um debate de posições e visões da relação de grupo entre os membros e sobre trabalho em grupo, nesse momento os coordenadores interviram e solicitaram que cada um esperasse o colega encerrar para falar. Assim, os coordenadores atuaram passando a palavra aos integrantes de forma organizada. Com isso, pode-se observar que como a associação atravessava uma troca de lideranças e presidência, esse contexto estava influenciando diretamente às relações entre os membros do grupo, gerando um movimento horizontal de ansiedade, e isso se mostrou na dificuldade de realizar as atividades grupais que, para serem realizadas, necessitavam de colaboração entre os participantes.

Para encerrar o encontro, os coordenadores retomaram os valores do grupo que era a união, amizade, respeito, o que foi concordado pelos membros do grupo. Um dos membros solicitou a observação e opinião dos coordenadores sobre a atual realidade do grupo. Os coordenadores aproveitaram o momento para se despedirem e agradecerem a experiência $e$ oportunidade de troca de conhecimentos.

\section{CONSIDERAÇÕES FINAIS}




\begin{abstract}
0 percurso formativo proposto pela disciplina coordenação de grupos e equipes proporcionou a consolidação do processo teórico-prático. As aprendizagens teóricas e 0 compartilhamento de experiências entre docente e alunos em sala de aula foram fundamentais para o planejamento, organização, execução e avaliação de cada encontro com a associação, ou seja, o preparo em sala de aula tinha a função do planejamento e avaliação de cada encontro. Nesse sentido, o processo formativo se deu plural, no momento que há orientação coletiva e acesso teórico, e singular, o que cada grupo e aluno faz com 0 conhecimento adquirido e compartilhado na prática.
\end{abstract}

A realização dos encontros com o objetivo de descrever a experiência de integração com os membros do grupo da associação dos usuários do centro de atenção psicossocial II foi uma vivência que se pôde desempenhar as habilidades e competências para que $\mathrm{o}$ psicólogo possa ter e aprimorar recursos para fazer grupos ao longo de sua formação e quando profissional. A troca de experiência com os usuários do centro de atenção psicossocial II foi extraordinária pois marcou como lidar com as diferenças em grupo.

No que se refere a integração, identidade e lugar de pertença de cada membro do grupo da associação, salienta-se que este estudo contribuiu para reflexões iniciais, que promoveu inquietação na medida que solicitaram contribuição com um planejamento estratégico como recurso para aprimorar as situações descritas na experiência.

\section{REFERÊNCIAS}

1. Rodrigues J, Brognoli FF, Spricigo JS. Associação dos usuários de um Centro de Atenção Psicossocial: Desvendando sua significação. Texto \& Contexto Enferm. 2006; 5:240-245.

2. Vasconcelos EM. Empoderamento de usuários e familiares em saúde mental e em pesquisa avaliativa/interventiva: uma breve comparação entre a tradição anglo-saxônica e a 
experiência brasileira. Ciênc Saúde Coletiva. 2013; 18(10):2825-2835 .

3. Vasconcelos EM, Rodrigues J. Organização de usuários e familiares em saúde mental no Brasil: uma contribuição para a IV Conferência Nacional de Saúde Mental - Intersetorial. In: Eduardo Mourão Vasconcelos (Org.). Desafios políticos da reforma psiquiátrica brasileira. São Paulo: Hucitec; 2010.

4. Zimerman D. A importância dos grupos na saúde, cultura e diversidade. Vínculo. 2007; 4(4):1-16.

5. Castilho A. A dinâmica do trabalho em grupo. Quality Mark. 3 ed. Rio de janeiro: Quality Mark; 2002.

6. Moscovici, F. Desenvolvimento Interpessoal: treinamento em grupo. Rio de Janeiro: José Olympio; 1998.

7. Offe C. Capitalismo desorganizado. São Paulo: Editora Brasiliense; 1994.

8. Florianópolis. Estatuto Social da Associação de Usuários do Centro de Atenção Psicossocial. Documento interno. Florianópolis; 2018.

9. Yozo RYK. 100 Jogos para grupos: uma abordagem psicodramática para empresas, escolas e clínicas. São Paulo: Agora; 1996.

10. Pedroso R, Medeiros RHA. Efeitos da reforma psiquiátrica no processo de acolhimento no caps ad em Viamão, RS. J Health NPEPS. 2016; 1(2):231-245.

Conflito de interesses: Os autores declaram não haver conflito de interesses.

Participação dos autores:

- Concepção: Rodrigues J, Kimura F, Nunes MEB, Barreto PAF, Luz AML.

- Desenvolvimento: Rodrigues J, Kimura F, Nunes MEB, Barreto PAF, Luz AML.

- Redação e revisão: Rodrigues J, Kimura F, Nunes MEB, Barreto PAF, Luz AML. 
Como citar este artigo: Rodrigues J, Kimura F, Nunes MEB, Barreto PAF, Luz AML. Estratégias de integração com a associação de usuários de um centro de atenção psicossocial. J Health NPEPS. 2020; 5(1):430-449.

Submissão: $13 / 03 / 2020$

Aceito: $01 / 06 / 2020$

Publicado: 01/06/2020 